\title{
Reputação, credibilidade e transparência da autoridade monetária e o estado de expectativa ${ }^{1}$
}

\author{
Gabriel Caldas Montes ${ }^{2}$ \\ Carmem Aparecida Feijo ${ }^{3}$
}

\begin{abstract}
Resumo
Para se desenvolver uma teoria que busca explicar como a política monetária afeta a economia é necessário entender como os indivíduos tomam decisões com base em suas expectativas e na confiança. Nesse sentido, torna-se fundamental conhecer os elementos determinantes das expectativas e da confiança dos agentes e como são afetados pela autoridade monetária. Tendo como referenciais teóricos (i) o esquema desenvolvido por Dequech (1999a) relacionado aos determinantes das expectativas e da confiança dos agentes; (ii) os pressupostos que fundamentam a nãoneutralidade da moeda; e (iii) a literatura que aborda a influência da reputação, da credibilidade e da transparência sobre a economia, o artigo tem como objetivo demonstrar a influência do trinômio credibilidade-reputação-transparência para o "estado de expectativa" dos indivíduos, e, assim, para a capacidade da política monetária em afetar emprego e renda, mantendo a estabilidade de preços.
\end{abstract}

Palavras-chave: Reputação (Direito) - Aspectos econômicos; Credibilidade; Transparência; Expectativa; Confiança.

\section{Abstract \\ Reputation, credibility and transparency of the monetary authority and the state of expectations}

For the development of a theory that looks for an explanation about how monetary policy affects the economy it is necessary to understand how economic agents make decisions based on their expectations and confidence. Therein, it is important to know the determinants of expectations and confidence and how these are affected by monetary authority. Using as theoretical references (i) the scheme developed by Dequech (1999a) about the determinants of expectations and confidence; (ii) the assumptions that support the non-neutrality of money; and (iii) the literature about reputation, credibility and transparency, the article seeks to demonstrate the influences of reputation-credibilitytransparency trinomial for the state of expectations of the agents, and, consequently, for the monetary policy capacity to affect employment and income keeping prices stability.

Key words: Reputation; Credibility; Transparency; Expectation; Confidence. JEL D84, E12, E52, E58.

(1) Trabalho recebido em agosto de 2006 e aprovado em março de 2007. Agradecemos os profícuos comentários do prof. Helder Ferreira de Mendonça (Universidade Federal Fluminense - UFF), de Fabio Batista Mota (Universidade Federal da Bahia - UFBA), e sugestões e comentários de parecerista anônimo, que no entanto não são responsáveis por falhas e omissões que persistam. Agradecemos também o apoio financeiro concedido pela Capes (Coordenação de Aperfeiçoamento de Pessoal de Nível Superior) e pelo CNPq (Conselho Nacional de Desenvolvimento Científico e Tecnológico).

(2) Doutorando em Economia na UFF e bolsista Capes.

(3) Professora da UFF e pesquisadora CNPq. 


\section{Introdução}

Teoricamente existem muitas controvérsias sobre os efeitos da política monetária na economia, embora haja concordância em relação às quatro principais metas finais a serem perseguidas, em conjunto ou isoladamente, pela política monetária: controle da inflação; expansão do nível de atividade econômica; redução da taxa de desemprego; e manutenção da estabilidade do sistema financeiro. Ainda em termos teóricos, aceitar ou rejeitar determinadas hipóteses, como por exemplo, a neutralidade da moeda, ou os motivos que explicam a preferência pela liquidez, ou a maneira como são formadas as expectativas dos agentes, traz consequiências diretas sobre os resultados dos modelos quando analisando a condução da política monetária.

Sob influência do advento da hipótese de expectativas racionais (HER), do debate acerca da utilização ou não de regras para a condução da política monetária, da teoria de independência do banco central e da opção pela adoção do regime de metas para a inflação, desenvolvimentos recentes em teoria monetária têm enfatizado a importância e a influência da reputação, da credibilidade e da transparência da autoridade monetária e suas políticas sobre a forma de conduzir a política monetária e sobre os resultados observados na economia.

Em relação aos rumos tomados pela linha de pesquisa tradicional (ortodoxa), deve ser enfatizado que à medida que os modelos de recomendações de política monetária se desenvolviam, incorporando a HER em suas estruturas, ganhava força a idéia de que políticas econômicas são mais efetivas se forem consideradas críveis pelos agentes econômicos e se forem implementadas por uma autoridade monetária com elevada reputação.

A combinação e aceitação dos seguintes pressupostos: (i) HER; (ii) hipótese de a economia funcionar baseada em um processo contínuo de equilíbrio de mercado e (iii) hipótese quanto ao caráter maximizador dos agentes, produz uma série de importantes conclusões a respeito das implicações causadas por políticas econômicas quando implementadas. Dentre essas implicações estão: a ineficácia da política monetária em afetar variáveis reais (neutralidade da moeda no curto e longo prazo); os custos que recaem sobre o emprego e o produto para se reduzir a inflação; a inconsistência temporal dinâmica de políticas discricionárias consideradas ótimas; a importância da credibilidade, da reputação e da transparência para a autoridade monetária; e o desenvolvimento de "tecnologias de compromisso" e regras que limitem a ação da autoridade monetária no sentido de se evitar o viés inflacionário.

Os argumentos relacionados à importância da credibilidade da política monetária para economias convivendo com taxa de inflação indesejada foram 
apresentados pela primeira vez por Fellner (1976, 1979). Posteriormente, Kydland e Prescott (1977) e também Barro e Gordon (1983a, 1983b) relacionaram a credibilidade da política monetária e a reputação da autoridade monetária e suas implicações ao problema de inconsistência temporal. A contribuição de Kydland e Prescott ${ }^{4}$ relacionada a esse tema encontra-se sob a forma de um modelo em que os policymakers estão envolvidos em um jogo dinâmico estratégico com agentes do setor privado que formam expectativas forward-looking de maneira sofisticada.

O insight fundamental promovido pelo modelo de Kydland e Prescott, relacionado à avaliação da política econômica, encontra-se associado à tentativa do governo de formular e implementar políticas ótimas em cada período, o que acaba gerando resultados subótimos para os períodos subseqüentes. Segundo o modelo desenvolvido por eles, políticas temporalmente inconsistentes tendem a enfraquecer a credibilidade das políticas a serem anunciadas e implementadas posteriormente.

Barro e Gordon (1983b), por sua vez, enfatizam o papel a ser desempenhado pela reputação da autoridade monetária. Argumentam que a persistência da inflação se deve à falta de reputação do policymaker devido ao não-cumprimento dos acordos previamente estabelecidos com a sociedade.

A fundamentação teórica que explica o desenvolvimento de trabalhos preocupados com a importância da credibilidade da política monetária e da reputação da autoridade monetária sobre a condução de suas políticas e seus resultados sobre a economia tem como base a literatura conhecida como "regras versus discrição" - iniciada com os trabalhos de Kydland e Prescott (1977) e Barro e Gordon (1983b).

Nesse sentido, o debate que trata do tema "regras versus discrição" em política monetária pode ser tomado como um fio condutor para uma discussão sobre as divergências teóricas entre Keynes e alguns de seus seguidores de um lado e monetaristas e novos-clássicos de outro. ${ }^{5}$

A corrente de pensamento pós-keynesiana direciona seus desenvolvimentos em teoria e política monetária para a fundamentação da nãoneutralidade da moeda no curto e no longo prazo. Assim, seus trabalhos apóiam-se

(4) Tiveram como inspiração o trabalho de Tinbergen (1952), pois, em um primeiro instante, buscam especificar as metas ou objetivos de política econômica e, em seguida, com base em uma função de bem-estar social que irão otimizar, selecionam os instrumentos de política econômica que serão utilizados em um modelo cujo objetivo é apontar as soluções ótimas encontradas.

(5) Em trabalho recente, Mendonça (2006, p. 181) obtém o seguinte corolário: "Na ausência de choques sobre a economia, o comportamento associado a regras apresenta resultados superiores ao comportamento discricionário. Por outro lado quando é removida a hipótese de que o Banco Central tem controle perfeito sobre a inflação, o comportamento discricionário, associado ao esforço adequado do responsável pela política monetária no controle da inflação, apresenta resultado superior". 
na teoria da preferência pela liquidez de Keynes e nas hipóteses de instabilidade do sistema financeiro (Minsky, 1992) e na formação de expectativas sob incerteza não probabilística. Sua modelagem também assume que expectativas são forwardlooking, porém, dada a hipótese de incerteza não probabilística, agentes sabem que a despeito de seus esforços, suas expectativas podem ser desapontadas. Essa possibilidade molda um comportamento em termos de formação de expectativas e tomada de decisões bastante distinto dos comportamentos modelados sob a HER.

Para desenvolver um modelo macroeconômico no qual a moeda afeta escolhas reais, Keynes contrapôs na Teoria geral o conceito de economia monetária de produção ao de economia de troca, que para ele seria o caso típico tratado pelos economistas clássicos. Assim, uma característica marcante de uma economia monetária de produção é o fato de a moeda não ser neutra nem no curto nem no longo prazo.

Na visão de Keynes, em economias monetárias de produção, a alocação de recursos depende da expectativa de demanda, que no agregado determina o nível de renda e emprego na economia. Essa característica torna naturalmente especulativa qualquer decisão econômica. Em decisões onde o horizonte de tempo é mais longo, por exemplo, a retenção de moeda e ativos líquidos se torna mais estratégica. Ou seja, quando o horizonte de tempo é o longo prazo, a moeda não é neutra pelo fato de sua retenção ser, também, uma forma de acumular riqueza, isto é, por ser considerada um ativo que afeta o processo de acumulação dos agentes. Assim, em uma economia monetária, a retenção de moeda é uma escolha racional num mundo de incerteza não probabilística. Contudo, ao optarem pela moeda ou por ativos com elevado grau de liquidez, os agentes econômicos estão deixando de alocar seus recursos no setor produtivo, quer seja na demanda por bens de capital quer seja em consumo. Ou seja, recursos podem ficar ociosos e a economia encontrar-se em equilíbrio abaixo do pleno-emprego. ${ }^{6}$

Nesse sentido, manipulações dos instrumentos de política monetária são capazes de afetar a economia por meio dos motivos que explicam a demanda por moeda realizada pelo público. A preferência pela liquidez reflete a percepção do

(6) No Tratado sobre a Moeda, publicado em 1930, ao identificar e distinguir dois circuitos de circulação da moeda - o industrial e o financeiro - Keynes elaborou as bases para sua teoria que explicaria os motivos que levam os agentes a reterem moeda, como isso afeta a economia e qual o papel a ser desempenhado pelo Estado no sentido de manter a economia operando próxima do pleno-emprego, mas, ao mesmo tempo, com estabilidade de preços. Posteriormente, em sua Teoria Geral, ao definir os fatores determinantes da demanda por moeda, reconhecendo e destacando que reter moeda é uma opção em relação à retenção de outros ativos, conforme o modelo de escolha de ativos do Capítulo 17, Keynes apresentou fundamentos para explicar as flutuações ocorridas no produto e o porquê de economias capitalistas operarem abaixo do pleno-emprego. Dentre os motivos que Keynes, em sua Teoria Geral, identificou para se demandar moeda estão: o transacional, o precaucional e o especulativo. O motivo finanças (finance) para se demandar moeda foi posteriormente incorporado por Keynes como resultado do debate com economistas clássicos em artigos publicados no Economic Journal em 1937. Para a recuperação desse debate, ver, por exemplo, Davidson (1965) e Oreiro (1999). 
público acerca dos eventos que esperam acontecer e que sejam capazes de afetar seus negócios: a preferência pela liquidez em Keynes é a forma como os agentes econômicos enfrentam as incertezas. Assim, intervenções realizadas pela autoridade monetária afetam a percepção dos agentes econômicos, influenciando a preferência pela liquidez e as decisões de produção e de investimento.

De um modo geral, para se entender como a política monetária afeta a economia é necessário compreender como agentes econômicos nela atuantes tomam decisões com base em suas expectativas e na confiança que possuem. Nesse sentido, torna-se fundamental conhecer os elementos determinantes das expectativas e da confiança dos agentes e como são afetados pela autoridade monetária. A literatura ortodoxa tem desenvolvido recentemente argumentos considerando a importância da transparência na formação das expectativas dos agentes. Conforme observado por Mendonça (2006, p. 178): "Dado que há o reconhecimento de que a efetividade da condução da política econômica depende de alguma forma de capacidade do público antecipar as ações do banco central; é esperado que a transparência ajude os agentes econômicos a prever melhor as ações da política monetária. Nesse sentido, a transparência contribuiria para o aumento da responsabilidade do banco central no alcance de suas metas anunciadas e, por conseguinte, para o aumento da credibilidade". A transparência da autoridade monetária é assumida como elemento essencial para reduzir o nível de incerteza na economia, já que atenua a existência de informação assimétrica entre autoridade monetária e demais agentes econômicos.

A proposta deste artigo é aprofundar o entendimento de como agentes econômicos formam suas expectativas partindo dos seguintes referencias teóricos:

(i) a contribuição de Dequech (1999a) que identifica, por meio de um esquema analítico, a influência do conhecimento, da criatividade e da disposição otimista do agente sobre sua confiança e suas expectativas, em um ambiente de incerteza fundamental e apresenta como resultado a capacidade de tais determinantes afetarem a preferência pela liquidez tornando válida a hipótese de não-neutralidade da moeda, e

(ii) a literatura referente à eficácia da política monetária, com destaque para os trabalhos sobre a reputação, a credibilidade e a transparência (doravante chamado de trinômio) da autoridade monetária e suas políticas.

A partir dessas referências, este artigo tem como objetivo identificar a maneira pela qual o trinômio influencia a confiança e as expectativas dos agentes econômicos, e, assim, a possibilidade de a política monetária afetar emprego e renda, mantendo a estabilidade de preços. Nesse sentido, o trabalho indica a possibilidade, por meio da influência do trinômio, de os indivíduos terem suas 
decisões de alocação de recursos afetadas pela autoridade monetária e suas políticas, resultando no rompimento com a idéia de neutralidade da moeda intrínseca nos modelos elaborados pela tradição ortodoxa. Indica também que, para que políticas monetárias que busquem estimular o produto e o emprego mantendo a estabilidade dos preços sejam bem-sucedidas, a autoridade monetária deve atuar de maneira pró-ativa, influenciando nas expectativas e na confiança dos agentes. Assim, é de suma importância entender o papel que desempenham as expectativas e a confiança dos agentes nas decisões de alocação de recursos e como a reputação da autoridade monetária e as considerações acerca da credibilidade e da transparência de suas políticas afetam tais decisões.

Com o intuito de demonstrar a possibilidade da política monetária em afetar não somente as variáveis nominais da economia, mas, também, o lado real, por meio da relação existente entre o trinômio e o processo de formação de expectativas dos agentes, o artigo encontra-se dividido da seguinte maneira: além desta introdução, a seção dois apresenta o papel do "estado de expectativa" para o processo de tomada de decisão dos agentes, destacando a influência das expectativas e da confiança sobre o processo de alocação de recursos em um ambiente de incertezas e, também, o papel das expectativas como mecanismo de transmissão da política monetária; a seção três discute a importância da credibilidade da política monetária e da reputação e transparência da autoridade monetária; a seção quatro mostra a relação entre o trinômio e o estado de expectativa dos agentes e como afeta as suas decisões; e a seção cinco, por fim, apresenta as considerações finais.

\section{Expectativas, confiança e política monetária}

Trata-se de um consenso entre economistas o fato de as expectativas serem consideradas um canal importante para a transmissão da política monetária. Com intuito de relacionar a influência do trinômio sobre a formação de expectativas, tomamos como base o esquema desenvolvido por Dequech (1999a). Esse busca identificar os elementos determinantes para as expectativas e para a confiança dos agentes, ou seja, para o "estado de expectativa", enfatizando sua importância como elemento de transmissão da política monetária. ${ }^{7}$ Dentre os determinantes do estado de expectativa que o esquema apresenta, destacamos o elemento "conhecimento" como fator capaz de afetar diretamente as expectativas e indiretamente a confiança por meio da incerteza percebida pelos agentes e, assim, afetar também suas decisões.

(7) Para uma apresentação mais detalhada a respeito dos mecanismos de transmissão da política monetária, ver Mendonça (2001). 


\subsection{0 estado de expectativas}

Dequech $(1999$ b, p. 67-68) define incerteza “... como uma situação na qual o conhecimento, devido à escassez de evidência, é incompleto e não confiável como um guia de conduta". Mais ainda, "incerteza fundamental" é definida como uma situação em que pelo menos alguma informação essencial acerca de eventos futuros não pode ser ou não é capaz de ser conhecida no momento em que uma decisão deve ser tomada, pois essa informação não existe e não pode ser inferida por nenhum conjunto de dados existente. Incerteza fundamental, como sugerida por Dequech, não implica completa ignorância acerca de todos os eventos que estão por ocorrer futuramente, porém diz respeito aos eventos fundamentalmente relevantes para o processo de tomada de decisões. Como destaca Heron (2003), podem ser identificadas duas fontes de incerteza na economia: uma, relacionada a eventos inesperados, tais como choques internos e externos sobre a economia e erros de previsão a respeito da política econômica, e outra, relacionada à falta de compreensão dos agentes econômicos quanto aos objetivos de longo prazo para a política monetária. ${ }^{8}$

$\mathrm{Na}$ ausência do pleno conhecimento necessário acerca de eventos que ainda estão por acontecer e/ou por imprecisão acerca da maneira como a economia funciona e é afetada por ações de políticas econômicas, os agentes formam expectativas e, com algum grau de confiança nessas expectativas, definem o "estado de expectativas" no qual as decisões irão se basear. Dequech (1999a), com o intuito de analisar os determinantes desse "estado", elabora um esquema analítico que apresenta os elementos que interferem na formação do estado de expectativas e como se inter-relacionam.

Seu esquema analítico se apresenta da seguinte maneira: (i) os determinantes imediatos do estado de expectativa são as expectativas e a confiança; (ii) a confiança é afetada diretamente pela aversão à incerteza e pela percepção à incerteza; (iii) as expectativas são afetadas diretamente pelo otimismo espontâneo, pelo conhecimento e pela criatividade; (iv) a aversão à incerteza é

(8) Heron (2003) enfatiza as incertezas que permeiam a compreensão que os agentes possuem acerca da política monetária que é implementada, assim como acerca do objetivo explícito que a autoridade monetária deva assumir, à luz do "novo consenso" macroeconômico. Os modelos elaborados pelo "novo consenso" (a exemplo, King, 2000; Romer, 2000; Taylor, 2000; Goodfriend, 2004; Woodford, 2003) são entendidos pelos seus proponentes como sendo representativos daqueles utilizados pelas principais autoridades monetárias, em que apresentam fundamentalmente as seguintes características: utilizam-se das hipóteses de expectativas racionais, neutralidade da moeda, existência de um processo de barganha no mercado de trabalho acerca do salário real, equilíbrio determinado pela oferta (ou seja, a demanda agregada é irrelevante para a determinação dos valores de equilíbrio das variáveis reais) e processo inflacionário explicado por pressões de demanda (excesso de demanda agregada é a principal fonte de inflação). Nesse sentido, sugerem, como forma de eliminar essas incertezas, que a autoridade monetária tenha como único e principal objetivo a obtenção de uma taxa de inflação baixa e estável e que esse objetivo seja alcançado por meio da adoção de uma regra explícita de política monetária.

Economia e Sociedade, Campinas, v. 16, n. 2 (30), p. 151-170, ago. 2007. 
influenciada pela disposição otimista ${ }^{9}$ (ou animal spirits); (v) a percepção à incerteza, por sua vez, pode ser explicada pela disposição otimista e pelo conhecimento; e (vi) o otimismo espontâneo é influenciado exclusivamente pela disposição otimista.

A variável-chave que estabelece a relação entre o trinômio e o "estado de expectativa" e que é considerada fundamental para o processo de tomada de decisões é a quantidade de conhecimento que se dispõe no momento da decisão. Como o completo conhecimento não existe no momento em que uma decisão econômica relevante deve ser tomada, os indivíduos fazem uso da informação disponível, de seu conhecimento tácito acerca do contexto em que estão inseridos e das instituições que os afetam e de sua criatividade em formar cenários prospectivos. ${ }^{10}$

Foray e Lundvall (1996) elaboraram uma taxonomia para o conhecimento, conceito que é muito mais amplo do que o de informação, estando esse último inserido no conhecimento. ${ }^{11}$ Distinguem quatro tipos de conhecimento, que são importantes de serem destacados, para melhor ilustrar o esquema a ser apresentado: 1) "know-what" (saber o quê); 2) "know-why" (saber por quê); 3) "know-how" (saber como), e; 4) "know-who" (saber quem).

Os diferentes tipos de conhecimento apresentados podem ser assim entendidos: Know-what refere-se ao conhecimento sobre os "fatos". Ou seja, esse conhecimento encontra-se próximo ao que é normalmente chamado de informação. Know-why refere-se ao conhecimento científico a respeito dos princípios e leis naturais. Esse tipo de conhecimento encontra-se bastante relacionado ao desenvolvimento tecnológico. Pode ser associado à percepção do agente quanto ao modo de funcionamento da economia. Know-how refere-se às habilidades ou capacidades de realizar algo. É tipicamente um tipo de conhecimento desenvolvido e mantido dentro dos limites de uma firma individual. Know-who refere-se à informação a respeito de quem sabe o quê e quem sabe fazer o quê. Envolve a formação de uma relação social especial que torna possível obter acesso a especialistas e utilizar seus conhecimentos eficientemente.

(9) Dequech (1999a, p. 421) argumenta que a disposição otimista não deve ser vista como puramente subjetiva ou psicológica, mas como, também, uma função do ambiente institucional em que o indivíduo opera, assim, "animal spirits are partly endogenous (and the more so, the more institutions are incorporated into one's analysis), partly exogenous".

(10) Segundo Shackle, os agentes preenchem os vazios de informação com "figments of imagination".

(11) De acordo com as abordagens pós-keynesiana, institucionalista e neo-austríaca, como apresenta Dow (1998, p. 221), o conjunto de informações relevantes para o processo decisório dos agentes constitui um subconjunto do conhecimento, sendo, portanto, o conhecimento um conjunto de informações e de saberes acerca de processos e modos de funcionamento da economia em diferentes situações em que se encontra. 
O conhecimento, nas suas várias formas, é um conjunto de saberes, tanto tácitos quanto codificados, que afeta o processo de tomada de decisões dos agentes por meio de diferentes elementos. Esses diferentes saberes formam o conhecimento que o agente possui quanto, por exemplo: ao acesso às informações e fatos relevantes para o processo de tomada de decisões, à percepção do agente a respeito de como funciona a economia (destacando como é afetado por ela e como a afeta), à maneira como irá reagir ou com que habilidade irá atuar quando inserido em diferentes cenários e a quem ou quais instituições são capazes de afetar seus negócios e de que maneira. No que esse conjunto de saberes se altera, a percepção à incerteza do agente se modifica, afetando, assim, sua confiança e suas expectativas.

O grau de confiança (Keynes, 1963, cap. 12) que determina o estado de expectativa do agente econômico é definido pela forma com que percebe as incertezas existentes e pela aversão à incerteza que possui. A aversão à incerteza é de caráter puramente subjetivo e psicológico, sendo resultado da disposição otimista do agente; já a maneira como o agente percebe a incerteza e a encara, em parte é resultado de seu conhecimento e em parte resultado de seu feeling ou animal spirit. Assim, a confiança do agente econômico depende de sua disposição otimista de encarar a incerteza e de como seu conhecimento influencia sua percepção acerca da incerteza. Pode-se estabelecer que quanto maiores forem a percepção acerca da incerteza e a aversão à incerteza - assumidas expectativas já formadas - maior será a tendência dos agentes a não tomarem ações relacionadas a longos horizontes de planejamento, adiando, portanto, tais decisões.

Em termos do processo de alocação de recursos, a escolha por não investir, ou seja, optar por alocar recursos em ativos com maior grau de liquidez representa essa escolha, pois, muito provavelmente, a percepção e a aversão à incerteza devem ser elevadas, influenciando negativamente a confiança. Dequech (1999a, p. 426) estabelece que: "The weaker the optimistic disposition, the stronger the liquidity preference and the larger the share of liquid assets in the decision maker's portfolio". Aqui, a escolha por um portfólio com maior ou menor grau de liquidez estará relacionada ao otimismo ou pessimismo associado ao "estado de expectativa".

A noção de estado de confiança é de grande importância prática, pois as decisões de investimento em ativos fixos requerem não somente previsões suficientemente otimistas acerca dos ganhos monetários prospectivos, mas, também, de um estado suficientemente forte de confiança que motive a implementação de planos de investimento produtivo. Como observado por Keynes, dado que a incerteza é um elemento no processo de formação das expectativas que não pode ser avaliado objetivamente, a variável relevante é o grau de confiança que os agentes atribuem às expectativas. 
Em resumo, pelo fato de a incerteza estar relacionada com a escassez de evidências, tornando o conhecimento incompleto, as decisões tomadas pelos agentes econômicos, em ambiente de incerteza, são afetadas por meio das expectativas e do grau de confiança depositada nessas expectativas. Nesse sentido, um importante papel a ser desempenhado pela autoridade monetária, por meio da política monetária, é aumentar ao máximo o nível de conhecimento na economia contribuindo assim para aumentar o grau de confiança nas expectativas.

\subsection{Expectativa como mecanismo de transmissão da política monetária}

Em Keynes, as condições de oferta - decisões de preço, produção e alocação de fatores - são afetadas pelas expectativas de demanda que por sua vez são capazes de serem afetadas pela política monetária. Assim, ao formarem suas expectativas, firmas avaliam as ações das autoridades monetárias e incluem essas avaliações nas suas expectativas.

Nesse sentido, as expectativas que orientam as decisões em uma economia monetária de produção são consideradas um relevante canal de transmissão da política monetária. As ações implementadas pelas autoridades monetárias, por sua vez, somente alcançarão o objetivo desejado se os agentes econômicos possuírem confiança ou crença suficiente nos resultados capazes de afetar os seus interesses. Dessa forma, funções comportamentais devem ser argumentadas por uma variável que represente a confiança do agente, ou sua crença.

Em suma, a confiança dos agentes se caracteriza como um elemento fundamental de propagação da política monetária pelo canal das expectativas, representando a percepção dos agentes econômicos quanto à postura da autoridade monetária e sua forma de conduzir a política monetária. Assim, uma relação pode ser estabelecida entre o "estado de expectativas" - que envolve as expectativas e a confiança dos indivíduos e firmas - e a reputação e transparência da autoridade monetária e a credibilidade de suas políticas.

\section{0 trinômio reputação-credibilidade-transparência}

De acordo com os principais desenvolvimentos que abordam o trinômio ${ }^{12}$, a ênfase dada ao conceito de credibilidade da política monetária encontra-se associada à capacidade da autoridade monetária em manter o compromisso com uma estratégia ou regra de condução da política monetária previamente estabelecida. Além do conceito de credibilidade da política monetária, a

(12) Estudos envolvendo tanto a credibilidade da política monetária quanto a reputação e a transparência da autoridade monetária foram desenvolvidos fundamentalmente pela ortodoxia econômica e com a preocupação de se observar os efeitos das políticas monetárias quando conduzidas ou sob regras ou de forma discricionária. 
capacidade da autoridade monetária em atingir seus objetivos encontra-se relacionada com a avaliação que o público faz a respeito da reputação da autoridade responsável pela política monetária. Nesse sentido, depende da confiança conquistada pela autoridade monetária, ou seja, de sua reputação, para que uma política monetária seja considerada crível ou não pelo público.

Credibilidade e reputação são, em essência, conceitos distintos. Enquanto credibilidade refere-se ao grau de confiança que o público possui em relação à determinação e habilidade da autoridade monetária em atingir os objetivos anunciados, ou seja, se as políticas (ou planos) são críveis, reputação encontra-se relacionada à crença do público quanto às preferências dos policymakers e às expectativas que o público forma acerca das ações a serem tomadas pela autoridade monetária. ${ }^{13}$

A construção da reputação da autoridade monetária encontra-se relacionada à sua capacidade de cumprir com os seus anúncios, à sua capacidade de fazer convergir as expectativas formadas pelo público para um determinado objetivo e à imagem institucional ${ }^{14}$ que o público possui a seu respeito. Nesse sentido, a formação da reputação da autoridade monetária tem como fundamento a avaliação do seu desempenho. ${ }^{15}$

Um outro elemento importante na conquista da reputação pela autoridade monetária, que deve ser destacado, é a transparência com que a autoridade monetária faz seus anúncios e com que conduz a política monetária. A transparência atua influenciando na capacidade de o banco central fazer convergir, mais rapidamente, as expectativas do público para os objetivos predeterminados.

O interesse cada vez maior acerca do papel que a transparência desempenha no processo de implementação e de condução da política monetária se reflete na crescente atenção que as autoridades monetárias de diversos países

(13) De acordo com Blinder (1999, p. 4): "A central bank is credible if people believe it will do what it says". A respeito do conceito de reputação, Drazen (2000, p. 168) argumenta que: "In everyday usage, 'reputation' often refers to generally held beliefs about an individual's (or a group's) character or characteristics. (...) Reputation can then be thought of in terms of the actions an agent is expected to take".

(14) Para maiores detalhes acerca da relação entre imagem institucional e reputação ver Vieira (2003). Seu trabalho teve como objetivo investigar a relevância da imagem institucional do Banco Central na construção de sua reputação. Vieira segue as definições de Martineau (1958) e Dowling $(1986,1993)$ a respeito do que venha a ser imagem institucional, isto é, considera-se "a imagem institucional como a percepção global da empresa em determinado momento do tempo". Vieira considera que a imagem institucional é um elemento distinto da reputação, mas que influencia fortemente sua determinação.

(15) A reputação da autoridade monetária é, portanto, um estado de percepção do público a respeito de um conjunto de fatores que envolvem as preferências reveladas pela autoridade monetária, as ações que os agentes esperam que a autoridade monetária tome e a crença que o público possui quanto ao caráter e características da autoridade monetária. Quando esses fatores se modificam de forma inesperada, podem surgir alterações na percepção à incerteza levando a um ambiente de deterioração do "estado de expectativa" do público por meio da confiança que depositam em suas expectativas.

Economia e Sociedade, Campinas, v. 16, n. 2 (30), p. 151-170, ago. 2007. 
têm reservado à comunicação de suas políticas. Quando o banco central consegue fazer com que os agentes econômicos compreendam a sua visão do ambiente econômico, compartilhando informações e conhecimento por meio de uma linguagem entendida pelos distintos segmentos do público, então há ampliação da transparência. De acordo com Vieira (2003, p. 112):

A exposição prévia da forma como o banco central reagirá ao aparecimento de contingências, permitirá que o público e o mercado compreendam sua lógica de atuação, o que reduz a probabilidade de uma interpretação equivocada de suas ações em vista de mudanças de cenário.

A demanda por um maior grau de transparência ${ }^{16}$ é um reflexo do desejo do público por mais conhecimento e informações relacionados às operações do banco central e ao modo de funcionamento da economia. Ou seja, é uma demanda por insumos (conhecimento) que entrarão no processo de produção das expectativas e da confiança capazes de afetar as decisões a serem tomadas pelos agentes econômicos. Como ressaltado por Mendonça (2006, p. 116): “... a transparência tem papel relevante para que o público compreenda o funcionamento da política monetária, e, como conseqüência, aumente a velocidade de convergência de suas expectativas para as metas anunciadas". Os benefícios da transparência na condução da política monetária se refletem, portanto, em termos de redução das incertezas e aumento da responsabilidade na condução da política monetária.

São sugeridos três resultados do efeito da transparência da autoridade monetária e suas políticas sobre a capacidade do setor privado de fazer previsão, sobre a reputação e sobre a credibilidade: (i) a transparência aumenta a capacidade de previsão de ações e resultados da política monetária; (ii) a transparência tende a induzir a construção de reputação, pois aumenta a sensibilidade das expectativas do setor privado relacionada a resultados e ações de políticas monetárias não antecipadas; e (iii) a transparência possui o potencial de aumentar a credibilidade da política monetária e fazer com que as expectativas de inflação do setor privado sejam mais estáveis no longo prazo.

Ao se trabalhar com os conceitos de economia monetária de produção, demanda efetiva e preferência pela liquidez, é aberta a possibilidade para situações econômicas em que a indução ao aumento do produto e do emprego, além da manutenção da estabilidade de preços, deve ser objeto da política monetária. Assim, a discussão sobre a influência da reputação, da credibilidade e da transparência da autoridade monetária e de suas políticas sobre a economia deve ser ampliada para se assumir a não-neutralidade da moeda e a capacidade da autoridade monetária em alcançar outros objetivos que não somente a inflação

(16) Geraats (2002) sugere cinco formas diferentes de transparência: transparência política, transparência econômica, transparência de procedimento, transparência de política e transparência operacional. 
baixa e estável. Em outras palavras, ao se ampliar o espectro de objetivos de política econômica, a interpretação sobre o significado do trinômio reputaçãocredibilidade-transparência na formação de expectativa dos agentes deve ser recolocada. Assim, a escolha pelo conceito de reputação da autoridade monetária como elemento de avaliação da autoridade monetária, em vez da credibilidade conceito mais bem associado às suas políticas - justifica-se pelos seguintes motivos:

(1) Ser um conceito capaz de conter uma carga menor de valores teóricos e ideológicos intrínsecos, pois os modelos tradicionais que abordam a importância da credibilidade da política monetária argumentam pela adoção de regras, dado que assumem expectativas racionais e neutralidade da moeda, o que para o pensamento pós-keynesiano representaria a subutilização da política monetária;

(2) Refletir a percepção que o público possui acerca da instituição que implementa as políticas e não a percepção acerca da política que está sendo implementada;

(3) Ser um elemento capaz de afetar a confiança e as expectativas do público.

A reputação da autoridade monetária é formada por acontecimentos pregressos, no entanto, é capaz de influenciar as expectativas que os agentes irão formar acerca de acontecimentos futuros. É de esperar, portanto, que uma autoridade monetária com elevada reputação e agindo com transparência faça convergir, de maneira mais acelerada, as expectativas do público para o objetivo pretendido.

Em suma, a reputação da autoridade monetária, como sugerida, é construída por meio da sua capacidade de implementar políticas econômicas, o que, num contexto de incerteza keynesiana associada a uma estrutura de economia sujeita a ocorrência de choques, implica a capacidade de perseguir de forma discricionária objetivos de política. A credibilidade da política econômica, nesse contexto, é mantida por meio do sucesso na coordenação de expectativas, reduzindo as incertezas. O compromisso de reduzir incertezas em grande medida é alcançado por meio de práticas transparentes de atuação da autoridade monetária.

A seção seguinte identifica como a autoridade monetária, por meio do trinômio, afeta o "estado de expectativas" dos agentes e, assim, os resultados observados para variáveis reais e nominais na economia. Deve ser destacado que a influência do trinômio não significa somente mais informação para a formação do "estado de expectativa", mas, também, mais conhecimento para o processo decisório dos agentes. A abordagem aqui apresentada contrapõe-se com a visão tradicional na qual o trinômio assume papel de oferecer mais informação, estando 
subentendido que os agentes detêm o conhecimento necessário para antecipar corretamente as ações a serem tomadas pelas autoridades monetárias.

\section{0 trinômio e sua influência sobre o estado de expectativa}

Para que a autoridade monetária possua maior capacidade de afetar o "estado de expectativa" dos agentes e, assim, por meio de intervenções monetárias atinja os objetivos predeterminados mais rapidamente e com maior eficácia, deve conquistar reputação, seguir políticas críveis e agir da forma mais transparente possível. Desse modo, reputação, credibilidade e transparência servem como catalisadores no processo de convergência das expectativas e da confiança do público para os objetivos previamente determinados pela autoridade monetária. A confiança do setor privado nas ações de política monetária e na própria autoridade monetária é determinante para a eficácia da política monetária que se propaga por meio das expectativas.

Os resultados pretendidos de serem alcançados pelas ações de política monetária por meio do canal das expectativas estão sujeitos à confiança do público na autoridade monetária e em suas políticas. A percepção à incerteza, que é afetada tanto pelo conhecimento que o público possui quanto pela sua disposição otimista, pode aumentar ou diminuir de acordo com a reputação da autoridade monetária, com o grau de transparência com que atua e com a credibilidade da política ou regime monetário que adota.

Como foi visto, a literatura aponta que a transparência da autoridade monetária e os sinais por ela emitidos atuam fortalecendo a credibilidade de suas políticas e aumentando sua reputação. Assim é de esperar que haja um impacto positivo de políticas monetárias bem formuladas sobre o lado real da economia, tendo como princípio a lógica de funcionamento de uma economia monetária de produção. Nesse sentido, a transparência e os sinais emitidos pela autoridade monetária revelam informações e conhecimento sobre o seu comportamento presente e futuro e, portanto, atuam no sentido de afetar as expectativas correntes e futuras que os agentes formam para variáveis como a inflação, o produto e o emprego. Isto é, o trinômio reputação-credibilidade-transparência afeta o ambiente institucional da política econômica e, nesse sentido, acaba por influenciar o estado de expectativa dos agentes.

Identificar o mecanismo pelo qual o trinômio exerce influência sobre as decisões a serem tomadas pelo setor privado envolve conhecer os elementos capazes de afetar o "estado de expectativas" dos indivíduos. O Quadro $1^{17}$ ilustra

(17) O Quadro 1 tem como referencial o esquema apresentado por Dequech (1999a). 
como o trinômio exerce influência sobre o estado de expectativa e, conseqüentemente, sobre as decisões dos agentes e a performance da economia.

O esquema apresenta a reputação, a credibilidade e a transparência afetando diretamente o conhecimento dos agentes. O elemento conhecimento influi tanto na percepção à incerteza quanto nas expectativas, sendo, por meio da percepção à incerteza, o canal pelo qual altera o grau de confiança dos agentes. $\mathrm{O}$ "estado de expectativa" que norteia as decisões de firmas, bancos e demais agentes econômicos de um modo geral será caracterizado ou como otimista ou como pessimista, de acordo com a influência do trinômio sobre o conhecimento.

Quadro 1

O trinômio e o estado de expectativa

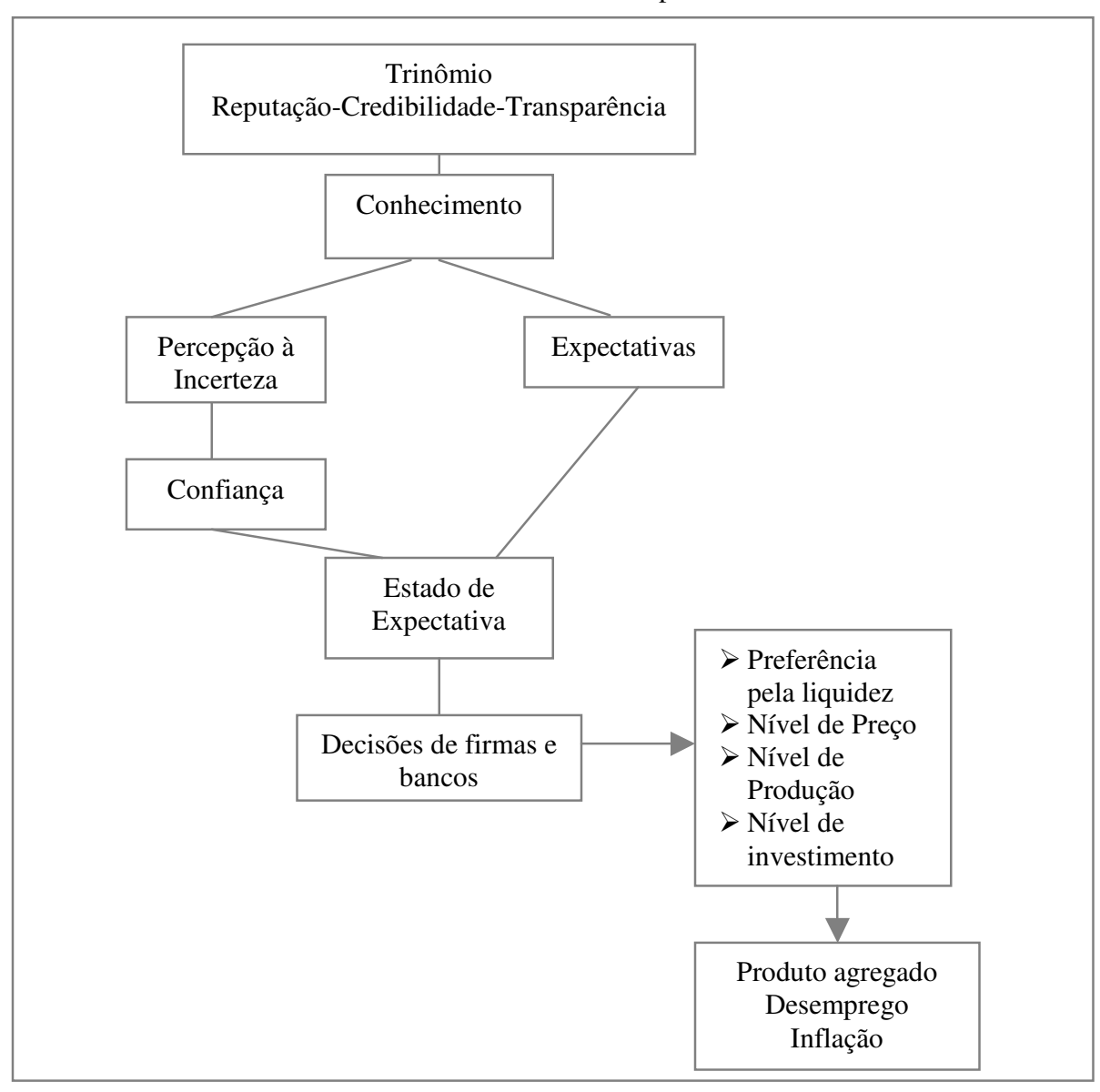

Deve ser ressaltado que, enquanto Dequech (1999a) relaciona uma situação de otimismo ou de pessimismo ao elemento "disposição otimista (animal spirits)", aqui otimismo e pessimismo encontram-se associados ao "estado de expectativas”. Dequech (1999a, p. 420) sugere o seguinte: 
In our scheme, situations of fundamental uncertainty are not reduced to a simple dichotomy between action and inaction; rather, there can be different types of action, depending on the quality and the intensity of the optimistic disposition. The idea to be conveyed is that of a disposition that comes in (ordinal) degrees and is combined with optimism or pessimism.

O esquema aqui apresentado pode ser assim explicado: uma autoridade monetária com elevada reputação, atuando por meio da implementação de políticas críveis e de forma transparente, tende a fazer com que o conhecimento dos indivíduos se amplie. Nesse sentido, a percepção à incerteza se reduz, aumentando a confiança nas expectativas formadas acerca de acontecimentos futuros e, conseqüentemente, gerando um estado de expectativa otimista. Tal otimismo se reflete na escolha por um portfólio de ativos voltado para obtenção de ganhos de longo prazo, ou seja, estimulando a escolha por ativos reais (investimentos), reduzindo a preferência pela liquidez e, assim, estimulando o produto e a renda da economia. Adquirir um ativo requer do investidor a avaliação de dois quesitos básicos: rentabilidade esperada e liquidez. Pelo fato de os títulos e a própria moeda possuírem um maior grau de liquidez em relação aos ativos de capital, a decisão de investimento será fundamentalmente influenciada pelas expectativas acerca das rentabilidades oferecidas pelos diferentes ativos. Uma política monetária que tenha como objetivo estimular a taxa de crescimento da economia deve estimular os agentes a trocarem liquidez por iliquidez e a trocarem rendimentos de juros por lucros, por meio da aquisição de bens de capital em vez de ativos financeiros. $\mathrm{O}$ estado de otimismo irá se refletir também na expectativa do público a respeito da capacidade da autoridade monetária em atingir os objetivos firmados para a inflação. Se o público acredita (espera) que as metas para a inflação serão alcançadas, pois a autoridade monetária revelou seu desejo pela manutenção de uma taxa de inflação baixa e estável e fará o que for necessário para que isso aconteça, então, acabam por reajustar preços e formar expectativas com base na meta.

Em outras palavras, sendo a preferência pela liquidez uma resposta às incertezas que permeiam a economia, uma autoridade monetária com elevada reputação e atuando de forma transparente por meio da implementação de políticas consideradas críveis deveria ser capaz, por exemplo, de conduzir o "estado de expectativa" do setor privado no sentido de estimular os investimentos em ativos fixos, ou seja, de promover a troca de ativos líquidos por ativos menos líquidos. ${ }^{18}$ No caso inverso, uma autoridade monetária com baixa reputação e atuando de forma opaca, ou seja, com baixo grau de transparência, exerce uma influência

(18) De acordo com Mollo (2004, p. 337): em momentos de incerteza e de baixo grau de confiança nas expectativas, a decisão de investir é comprometida porque as pessoas preferem a liquidez da moeda, retendo-a, o que inibe o investimento e, via efeito multiplicador, restringe ainda mais o crescimento da renda e do emprego. Esta é a fonte da não-neutralidade para Keynes e os pós-keynesianos. 
sobre os agentes econômicos no sentido de induzi-los a preferirem a liquidez, além de enfrentar maiores dificuldades para manter a taxa de inflação baixa e estável.

Em um mundo onde decisões são tomadas com base em expectativas sobre um futuro incerto, instituições são criadas para dar confiança às expectativas e com isso viabilizar as operações econômicas. Dentre as instituições mais importantes numa economia monetária de produção encontram-se a autoridade monetária e suas políticas. Exatamente pela sua capacidade de influir em resultados reais na economia, a sua gestão é determinante para a estabilidade do estado de expectativas.

\section{Considerações finais}

Tendo como referenciais teóricos a literatura que aborda a influência da reputação, da credibilidade e da transparência sobre a economia e o esquema desenvolvido por Dequech acerca dos elementos determinantes do "estado de expectativas", o artigo propõe que para a consolidação de um estado de expectativas positivo, que permita a contínua ampliação de renda e emprego com estabilidade de preços, é necessário que a autoridade monetária tenha uma boa reputação e adote práticas transparentes na condução da política econômica. Sua capacidade em induzir os agentes a trocarem posições mais líquidas por menos líquidas, aumentando o nível de demanda agregada na economia, depende da adoção de políticas econômicas planejadas segundo um sólido conhecimento de como agentes econômicos decidem sob incerteza.

A teoria de uma economia monetária de produção permite entender como as decisões de firmas e consumidores, tomadas isoladamente e em um ambiente de incerteza, são determinantes para o nível de preços e de produto agregados, sendo a política monetária capaz de afetar ambas as decisões por meio dos motivos que explicam a preferência pela liquidez dos agentes. A não-neutralidade da moeda justifica a capacidade da política monetária em afetar os motivos que levam os agentes a preferirem ou não a liquidez, provocando, assim, flutuações no produto e nos preços. A política monetária que tenha como objetivo o aumento do investimento e do ritmo de crescimento da economia se depara com agentes econômicos agindo orientados pelas suas expectativas e pelos sinais emitidos pelo banco central. Assim, a autoridade monetária deve sinalizar no sentido de estimular o escoamento de moeda da circulação financeira em direção à circulação industrial.

Contrário à ênfase do pensamento tradicional, que defende a busca somente da estabilidade da inflação e das expectativas para a inflação por parte da autoridade monetária por meio de uma política econômica crível, o pensamento de inspiração keynesiana propõe objetivos mais amplos para a política econômica. 
Ao assumir a não-neutralidade da moeda e ao reconhecer que o público não somente forma expectativas para a inflação, mas, também, para eventos que sejam capazes de afetar a lucratividade de seus negócios a longo prazo, é conferido ao banco central um campo de atuação muito mais amplo do que o proposto pela ortodoxia. Para os keynesianos, a política econômica, mais do que adicionar informação para a formação de expectativas dos agentes, é um elemento a acrescentar conhecimento sobre o funcionamento da economia.

Conforme Keynes e pós-keynesianos, existem inúmeras situações de equilíbrio na economia associadas aos diferentes tipos de políticas implementadas, logo, uma política monetária crível será aquela implementada por uma instituição com capacidade de coordenar expectativas e reduzir incertezas dos agentes. $\mathrm{O}$ resultado bem-sucedido de políticas com esse teor é o de reforçar a confiança dos agentes atuando sobre o estado de expectativas. A eficácia da política monetária encontra-se, portanto, condicionada à reação dos agentes econômicos. Ou seja, depende tanto da forma como os instrumentos são manipulados, como, também, das avaliações a respeito dos acontecimentos futuros que os agentes econômicos realizam quanto ao comportamento da demanda agregada. Se existir uma autoridade monetária capaz de emitir sinais e implementar políticas que direcionem as decisões dos agentes no sentido dos resultados que busca atingir, então, essa autoridade monetária será responsável por uma maior contribuição para esses resultados observados.

Em suma, as expectativas empresariais sobre a demanda futura são determinantes para emprego e produto por meio das decisões de produção e investimento. Tanto a figura da autoridade monetária quanto suas políticas são poderosos elementos capazes de afetar os resultados observados na economia, pois influem na formação das expectativas e da confiança dos agentes.

\section{Bibliografia}

BARRO, R. J.; GORDON, D. B. A positive theory of monetary policy in a natural rate model. Journal of Political Economy, v. 91, n. 41, 1983a.

Rules, discretion and reputation in a model of monetary policy. Journal of Monetary Economics, v. 12, n. 1, p. 101-122, 1983 b.

BLINDER, A. S. Central Bank credibility: why do we care? How do we build It? Cambridge: NBER, Jun. 1999. (Working Paper Series, n. 7161).

DAVIDSON, P. Keynes's finance motive. Oxford Economic Papers, v. 17, n. 1, p. 47-65, 1965.

DEQUECH, D. Expectations and confidence under uncertainty. Journal of Post Keynesian Economics, v. 21, n. 3, Spring 1999a.

Uncertainty, conventions and short-term expectations. Brazilian Journal of Political Economy, v. 19, n. 3 (75), Jul./Sept. 1999b. 
DOW, S. C. Knowledge, information and credit creation. In: NEW Keynesian economics/Post Keynesian alternatives. Routledge, 1998.

DOWLING, G. R. Managing your corporate image. Industrial Marketing Management, v. 15 , p. $109-115,1986$.

DRAZEN, A. Political economy in macroeconomics. Princeton University Press, 2000.

FELLNER, W. J. Towards a reconstruction of macroeconomics: problems of theory and policy. American Enterprise Institute, 1976.

. The credibility effect and rational expectations: implications of the Gramlich study. Brookings Papers on Economic Activity, Washington, DC, n. 1, p. 167-190, 1979.

FORAY, D.; LUNDVALL, B. The knowledge-based economy: from the economics of knowledge to the learning economy. In: OECD. Employment and growth in the knowledge economy. Paris: OECD, 1996.

. The credibility effect and rational expectations: implications of the Gramlich study. Brookings Papers on Economic Activity, Washington, DC, n. 1, p. 167-190, 1979.

GERAATS, P. M. Central Bank transparency. The Economic Journal, 112, Nov. 2002.

Transparency of monetary policy: theory and practice. University of Cambridge, Dec. 2005.

GOODFRIEND, M. Monetary policy in the new neoclassical synthesis: a primer. Federal Reserve Bank of Richmond Economic Quarterly, v. 90, n. 3, Summer 2004.

HERON, E. L. A new consensus on monetary policy? Revista de Economia Política, v. 23, n. 4 (92), out./dez. 2003.

KEYNES, J. M. The General Theory of employment, interest and money. London: Macmillan Press, 1936.

. The collected writings of J. M. Keynes. London: Macmillan (vários volumes).

A treatise on money. v. 2: The applied theory of money. London: Macmillan, 1971. (The Collected Writings of J. M. Keynes, v. 6).

KING, R. G. The new IS-LM model: language, logic, and limits. Federal Reserve Bank of Richmond Economic Quarterly, v. 86, n. 3, Summer 2000.

KYDLAND, F. E.; PRESCOTT, E. C. Rules rather than discretion: the inconsistency of optimal plans. Journal of Political Economic, v. 85, n. 3, 1977.

MARTINEAU, P. Sharper focus for the corporate image. Harvard Business Review, v. 36, n. 6, p. 49-58, Nov./Dec. 1958.

MENDONÇA, H. F. de. Mecanismos de transmissão monetária e a determinação da taxa de juros: uma aplicação da Regra de Taylor ao caso brasileiro. Economia e Sociedade, Campinas, n. 16, jun. 2001.

A teoria da credibilidade da política monetária: desdobramentos do debate regras versus discrição. Revista de Economia Política, v. 22, n. 3 (87), p. 46-64, jul./set. 2002. 
Gabriel Caldas Montes / Carmem Aparecida Feiió

MENDONÇA, H. F. de. Transparência, condução da política monetária e metas para a inflação. Nova Economia, Belo Horizonte, v. 16, n. 1, p. 175-198, jan./abr. 2006.

MINSKY, H. P. The financial instability hypothesis. The Jerome Levy Economics Institute of Bard College, May 1992. (Working Paper, n. 74).

MOLLO, M. L. R. Ortodoxia e heterodoxia monetárias: a questão da neutralidade da moeda. Revista de Economia Política, v. 24, n. 3 (95), jul./set. 2004.

OREIRO, J. L. O debate sobre os determinantes da taxa de juros. In: PAULA, Luiz Fernando de; SICSÚ, João (Org.). Macroeconomia moderna: Keynes e a economia contemporânea. Rio de Janeiro: Editora Campus, 1999.

ROMER, D. Keynesian macroeconomics without the LM curve. Journal of Economic Perspectives, v. 14, n. 2, Spring 2000.

SHACKLE, G. L. S. Expectations in economics. Cambridge University Press, 1952.

Expectation, enterprise and profit: the theory of the firm. London: George Allen \& Unwin, 1970.

New tracks for economic theory. In: WEINTRAUB, Sidney (Ed.). Modern economic thought. Philadelphia: University of Pennsylvania Press, 1977.

TAYLOR, J. B. Teaching modern macroeconomics at the principles level. American Economic Review, v. 90, n. 2, 2000.

TINBERGEN, J. On the theory of economic policy. Amsterdam: North Holland, 1952.

VIEIRA, P. R. C. Imagem e reputação do Banco Central: relação entre percepção de desempenho e compromisso institucional. Tese (Doutorado)-Universidade Federal do Rio de Janeiro, Instituto COPPEAD de Administração, Rio de Janeiro, 2003.

WOODFORD, M. Interest and prices: foundations of a theory of monetary policy. Princeton: Princeton University Press, 2003. 